Ege Tıp Dergisi / Ege Journal of Medicine 2019;58(2):184-186

\title{
Ekstübasyon aşamasında gelişen Takotsubo sendromu: Olgu sunumu
}

\author{
Takotsubo syndrome occurring during extubation phase: Case report \\ İlkben Günüşen (IIIrfan Tuna Düşgün (D) Özlem Yakut Özdemir(D \\ Ege Üniversitesi Tıp Fakültesi, Anesteziyoloji ve Reanimasyon Anabilim Dalı, İzmir, Türkiye
}

\section{Öz}

Takotsubo sendromu sıklıkla yanlış tanı konulan, nadir bir hastalıktır. Sol ventrikülün apikal ve orta segmentlerinde geçici, reversibl bölgesel duvar hareket kusuru vardır ve elektrokardiyografi (EKG) değişiklikleri ile akut miyokard infarktüsünü taklit eder. Genellikle büyük bir duygusal stres veya ciddi tıbbi rahatsızlıktan sonra görülür, aynı zamanda cerrahi stresle de ilişkili olabilir. Perioperatif dönemin hastalarda stres oluşturduğu iyi bilinir ve özellikle genel anestezi sırasında akut miyokard enfarktüsünü taklit eden elektrokardiyografi değişiklikleri gösteren bir hastada bu tanı düşünülmelidir. Ekstübasyon evresinde meydana gelen Takotsubo sendromlu bir olgu sunmayı amaçladık.

Anahtar Sözcükler: Takotsubo sendromu, kardiyomiyopati, genel anestezi.

\begin{abstract}
Takotsubo syndrome is a rare disorder which is often misdiagnosed. It is a form of transient, reversible regional wall motion abnormality in the apical to mid segments of the left ventricle and mimicking acute myocardial infarction with electrocardiographic changes. It is typically seen after a major emotional stress or serious medical illness, but could also be associated with the stress of the surgery itself. The perioperative period is well known to induce stress in patients, and this diagnosis should be considered when a patient presents with electrocardiographic changes mimicking acute myocardial infarction, especially during the general anesthesia. We aimed to present a case with Takotsubo syndrome occurring during the extubation phase.
\end{abstract}

Keywords: Takotsubo syndrome, cardiomyopathy, general anesthesia.

\section{Giriş}

İlk kez Japonlarda tanımlanan bu sendrom, koroner arter hastalığı olmaksızın akut myokard infarktüsüne benzer EKG değişiklikleri (ST segment yükselmesi, negatif T dalgası vb.), sol ventrikül apikal ve orta segmentlerinde görülen geçici disfonksiyon ile karakterizedir. Sol ventrikül apikalinde saptanan balon görüntüsü Takotsubo adı verilen ahtapot yakalamakta kullanılan bir kaba benzediği için bu isim verilmiştir (1-3). Görülme oranı \%0.7-2.5 olan ve sıklıkla postmenapozal kadınlarda ortaya çıkan bu sendromun patofizyolojisi, kesin olarak bilinmemekle birlikte katekolaminlerin rol oynadığı düşünülmektedir (1). Ayrıca genetik faktörler üzerinde durulmakta ve bazı kişilerin genetik yatkınlığı olabileceği ileri sürülmektedir. Genellikle duygusal (ani ölüm, hastalık haberi) ya da fiziksel (astım atağı, cerrahi gibi) bir stresi ya da akut tıbbi bir durumu takiben gelişir (1,3-5).

\footnotetext{
Yazışma Adresi: Illkben Günüşen

Ege Üniversitesi Tıp Fakültesi, Anesteziyoloji ve Reanimasyon Anabilim Dalı, İzmir, Türkiye

E-mail: ilkben.gunusen@ege.edu.tr

Makalenin Geliş Tarihi:29.01.2018 Kabul Tarihi: 21.02.2018
}

Hastaların büyük kısmında başlangıçta tipik göğüs ağrısı ve dispne bulunur. EKG değişiklikleri geri dönüşümlüdür ve akut fazda natriüretik peptit (BNP veya NT-proBNP) belirgin yükselir, kardiyak enzimlerde ılımlı artış saptanır $(1,5,6)$.

Akut koroner olayı taklit eden ve genellikle yanlış tanı alan bu hastalık, günümüzde artan sayıda olgu sunumlarının yayınlanmasıyla fark edilmeye başlanmıştır (1,6-10). Bu olguda, ekstübasyon aşamasında ST değişiklikleri ve aritmi görülen, ileri tetkikler sonucu Takotsubo sendromu tanısı alan bir hastayı sunmayı amaçladık.

\section{Olgu Sunumu}

Otuz altı yaşında, Japon asıllı olan ancak ülkemizde yaşayan, The American Society of Anesthesiologists (ASA) II sınıfına dahil kadın hastaya genel anestezi altında açık septoplasti operasyonu planlandı. Preoperatif değerlendirmesinde, hipotiroidi öyküsü nedeniyle levotiroksin kullanımı, geçirilmiş diz operasyonu ve infertilite tedavisi dışında herhangi bir özellik saptanmadı. Operasyon öncesi yapılan tam kan sayımı, tiroid fonksiyon testleri ve biyokimyasal tetkikleri normal olarak değerlendirildi. Bazal kan basıncı: 110/85 
$\mathrm{mmHg}$, kalp atım hızı: 85 atım/dk olan hasta oldukça stresli ve duygusal bir yapıya sahip olduğunu belirtmişti. $\mathrm{Bu}$ nedenle damar yolu açılarak iv $2 \mathrm{mg}$ midozalam ile premedikasyon sonrası, $10 \mu \mathrm{g} / \mathrm{kg}$ atropin, $3 \mathrm{mg} / \mathrm{kg}$ propofol, $1 \mu \mathrm{g} / \mathrm{kg}$ fentanil, $0.6 \mathrm{mg} / \mathrm{kg}$ rokuronyum ile standart anestezi indüksiyonu uygulandı. Sorunsuz tek seferde orotrakeal entübe edilen hastanın anestezi idamesi \%50 hava ve oksijen karışımı, 0.5-1 MAC sevofluran, $0.25-0.5 \mu \mathrm{g} / \mathrm{kg} / \mathrm{sa}$ remifentanil infüzyonu ile sağlandı. Yaklaşık $130 \mathrm{dk}$ süren operasyon sırasında hemodinamik açıdan stabil seyreden hastanın operasyon sonuna doğru remifentanil infüzyon dozu azaltıldı, cerrahinin tamamlanmasıyla sevofluran inhalasyonu ve remifentanil infüzyonu kesilerek \%100 oksijenle ventilasyona geçildi. Dekürarizasyon için iv 10 $\mu \mathrm{g} / \mathrm{kg}$ atropin ve $30 \mu \mathrm{g} / \mathrm{kg}$ neostigmin uygulaması sonrası spontan solunumu ve kas tonusu yeterli olan hastanın ekstübasyon aşamasında EKG de ST elevasyonu ve ventriküler erken vuruların geliştiği görüldü. İntravenöz $1 \mathrm{mg} / \mathrm{kg}$ lidokain sonrası ventriküler erken vuruların düzeldiği ST elevasyonunun ise kısmen azaldığı saptandı. Yaklaşık $5 \mathrm{dk}$ sonra ekstübe edilerek postoperatif bakım ünitesine alındı. Çekilen EKG de prekordial ST segment elevasyonu, ventriküler erken vurular ve QT segmentinde uzama saptandı. Bilinç açık, göğüs ağrısı ve solunum sıkıntısı olmayan hastaya kardiyoloji konsültasyonu istendi. Troponin (21 ng/L) dışındaki tüm laboratuvar değerleri normal olan hasta, 6 saat sonra alınan kontrol kanda troponin $393 \mathrm{ng} / \mathrm{L}$, CKMB Mass: $9.56 \mathrm{ng} / \mathrm{mL}$ saptanması üzerine akut koroner sendrom düşünülerek koroner yoğun bakıma yatırıldı. Beta bloker ve antikoagulan tedavi başlanan hastanın çekilen anjiyografisinde koroner damarlarda darlık saptanmazken EKO da ejeksiyon fraksiyonu (EF) \%40 idi. Sol ventrikülografide ise belirgin antero-apikal ciddi duvar hareket kusuru ve apeks de geçici anevrizmatik genişlemeler görülerek Takotsubo sendromu tanısı konuldu. Postoperatif 3. günde NT-pro BNP 2190 pg/mL, troponin $56 \mathrm{ng} / \mathrm{L}$ olan hasta, hemodinamik açıdan stabil seyretmesi üzerine kardiyoloji servisine alındı. Postoperatif 7. günde çekilen EKO da EF normal saptandı ve kardiyak enzimlerin düşmesi üzerine poliklinik kontrolü önerilerek taburcu edildi.

\section{Tartışma}

Perioperatif dönem, operasyon öncesi yaşanan heyecan, korku, anksiyeteye bağlı duygusal strese hem de operasyon sırasında görülen durumlara bağlı olarak (özellikle yüzeyel anestezi, entübasyon ve ekstübasyon sırasındaki trakea manipülasyonları, laringoskopi, hipoksemi, tekrarlayan entübasyon girişimleri, ekzojen epinefrin, katekolamin uygulamaları vb.) fiziksel strese yol açan bir durumdur $(6,10)$. Literatürde hastaların yaklaşık \%70'inden fazlasında epinefrin ve norepinefrinin aşırı salınımı sonucu sempatik uyarının rolü üzerinde durulan Takotsubo sendromu, son yıllarda ülkemizde yayınlanan olgu sunumları ile fark edilmeye başlanmıştır Cilt 58 Sayı 2, Haziran 2019 / Volume 58 Issue 2, June 2019
(8-10). Hastalığı tetikleyen faktörler arasında ekzojen katekolamin uygulamalarının yanı sıra ciddi hipotiroidi gibi endokrin bozukluklar da sayılmaktadır (6). Hastamızda hipotiroidi öyküsü olmasına karşın TFT değerleri operasyon öncesi normaldi. Ayrıca operasyon sırasında vazopressör tedavi uygulanmamıştı. Yakın geçmişte infertilite tedavilerine bağlı yaşadığı duygusal streslere, cerrahi girişimin neden olduğu stresin de eklenmesinin bu hastalığın gelişmesine katkı sağladığını düşünüyoruz. Ayrıca Japon asıllı olması nedeniyle genetik faktörler de predispozan rol oynamış olabilir.

Agarwal ve ark. (6) perioperatif dönemde Takotsubo sendromu gelişen 102 vakayı inceledikleri çalışmalarında \%41.2'nin intraoperatif (en sık indüksiyon aşaması ve cerrahinin ilk yarısı), \%58.8'nin ise postoperatif dönemde (sıklıkla erken dönem) görüldüğü ve hastaların \%65.7'ne genel anestezi uygulandığını belirtilmiştir. Ancak belli bir anestezi ya da cerrahi tipinin bu sendromla ilişkisi gösterilememiştir. Her türlü cerrahi ve anestezi uygulamaları (genel, santral ve periferik bloklar dahil) sırasında Takotsubo sendromunun gelişebileceği belirtilmektedir (6,8-10).

Östrojen, oksidatif stresin hafifletilmesi, sempatik nöromodülasyonun etkilenmesi, $\quad \beta$-reseptörlerin duyarlıı̆̆ının azalması ve endotel fonksiyonunun iyileştirilmesinde önemlidir. Postmenapozal dönemde kadın hastalarda yaygın görülmesinin, azalmış östrojen seviyesi ile ilişkili olabileceği belirtilmektedir. Ancak erkeklerde ve genç yaştaki kadınlarda da görülebilir. Özellikle intraoperatif dönemde gelişen Takotsubo sendromunun bizim hastamızda olduğu gibi daha genç yaş grubunda ortaya çıktığı da bildirilmektedir $(1,6,7,9,10)$.

Hastalarda göğüs ağrısı, dispne gibi semptomların başlangıçta sıklıkla görüldüğü belirtilmektedir $(2,7)$. Ancak Agarwal ve ark. hastaların ancak \%28.4'ünde göğüs ağrısı, \%21.6'ünde ise dispne semptomunun olduğunu, buna karşın ST değişiklikleri ve aritminin daha sık geliştiğini saptamıştır (6). Hastamızda da postoperatif dönemde göğüs ağrısı ve dispne bulguları yoktu. Prekordiyal derivasyonlarda ST segment yükselmesi hastaların \%59-100, patolojik $Q$ dalgalarının ise \%631'inde görüldüğü bildirilmektedir(1). Olgumuzda da ekstübasyon aşamasında ST değişiklikleri ve ventriküler erken vuru dışında herhangi bir semptom saptanmadı. Hastanın genç olması, kardiyak öykü, perioperatif hipoksi, hipotansiyon vb. bulunmaması nedeniyle başlangıçta gelişen EKG değişikliklerini yorumlayamamıştık. Aslında bu sendromu sadece klinik ve EKG değişiklikleri ile gerçek akut miyokard infarktüsünden ayırt etmek zordur. Koroner anjiyografide darlık saptanmaması, ayırıcı tanıda kullanılan en iyi yöntemdir $(1,4)$. Hastamızda EF'nin düşük, koroner anjiografinin normal, ventrikülografide tipik apikal balon görüntüsü ve duvar hareket kusurunun saptanması ile tanı konulabildi. 
Ciddi komplikasyonlar gelişebilirse de çoğu hastada prognoz iyi ve tekrarlama riski nadirdir. Genellikle ventrikül fonksiyonlarının ve troponin seviyelerinin bir hafta gibi kısa sürede normale döndüğü ve hastaların taburcu edildiği bildirilmiştir $(3,4,6,7)$. Operasyon öncesi hastalarla iyi iletişim kurulması, yeterli düzeyde bilgilendirme yapılması, özellikle yakın dönemde ciddi psikolojik stres (aile trajedi, boşanma, dava vb.) yaşayan kişilerin fark edilmesi, bu hastalığa yatkın olanların belirlenmesinde yararlı olabilir $(4,6)$.

Sonuç olarak, perioperatif dönemin hastalarda stres oluşturduğu bilinir. Bu dönemde miyokard infarktüsünü taklit eden EKG değişiklikleri ya da aritmi durumunda Takotsubo sendromunun akılda tutulması gerektiğini düşünüyoruz.

\section{Kaynaklar}

1. Veillet-Chowdhury M, Hassan SF, Stergiopoulos K. Takotsubo cardiomyopathy: A review. Acute Card Care 2014;16(1):15-22.

2. Scantlebury DC, Prasad A. Diagnosis of Takotsubo cardiomyopathy. Circ J 2014;78(9):2129-39.

3. Kurisu S, Kihara Y. Clinical management of Takotsubo cardiomyopathy. Circ J 2014;78(7):1559-66.

4. Jabaudon M, Bonnin M, Bolandard F, Chanseaume S, Dauphin C, Bazin JE. Takotsubo syndrome during induction of general anaesthesia. Anaesthesia 2007;62(5):519-23.

5. Lyon AR, Bossone E, Schneider B, et al. Current state of knowledge on Takotsubo syndrome: A Position Statement from the Taskforce on Takotsubo Syndrome of the Heart Failure Association of the European Society of Cardiology. Eur J Heart Fail 2016;18(1):8-27.

6. Agarwal S, Bean MG, Hata JS, Castresana MR. Perioperative Takotsubo cardiomyopathy: A systematic review of published cases. Semin Cardiothorac Vasc Anesth 2017;21(4):277-90.

7. Littlejohn FC, Syed O, Ornstein E, Connolly ES, Heyer EJ. Takotsubo cardiomyopathy associated with anesthesia: Three case reports. Cases J 2008;1(1):227.

8. Deniz S, Bakal Ö, İnangil G, Şen H, Özkan S. Takotsubo cardiomyopathy occurring in the postoperative period. Turk J Anaesthesiol Reanim 2015;43(1):47-9.

9. Küçükdurmaz Z, Karapınar $\mathrm{H}$, Oflaz $\mathrm{MB}$ ve ark. Takotsubo kardiyomiyopatisi hakkında klinik deneyimimiz ve ülkemizden bildirilen ilk olgu serisi. Türk Kardiyol Dern Arş 2013;41(3):212-7.

10. Erkal Z, Bayar N, Küçükseymen S, Çağırıcı G. Arslan Ş. Kolesistektomi operasyonu sonrası gelişen Takotsubo kardiyomiyopatisi. MN Kardiyoloji 2015;22(1):37-9. 